\title{
The significance of mineral inclusions in large diamonds from Yakutia, Russia
}

\section{Lawrence A. Taylor, ${ }^{1,}$ * Mahesh Anand, ${ }^{1}$ Prinya Promprated, ${ }^{1}$ Christine Floss, ${ }^{2}$ And Nikolai V. SOBOLEV ${ }^{3}$}

\footnotetext{
${ }^{1}$ Planetary Geosciences Institute, Department of Earth \& Planetary Sciences, University of Tennessee, Knoxville, Tennessee 37996, U.S.A. ${ }^{2}$ McDonnell Center for Space Sciences, Washington University, St. Louis, Missouri 63130, U.S.A.

${ }^{3}$ Institute of Mineralogy and Petrography, Russian Academy of Sciences, Siberian Branch, Novosibirsk 630090, Russia
}

\begin{abstract}
Large diamonds (10-200 carats) from Udachnaya, Mir, and Aikhal kimberlite pipes of Yakutia contain variable mineral inclusions typical of diamonds of smaller size. Among these inclusions, extracted from outer portions of these diamonds, the majority are garnets of harzburgitic paragenesis, with a small number of inclusions belonging to lherzolitic and eclogitic groups, in addition to chromite diamond inclusions (DIs). The most striking feature of the garnet DIs is the sinusoidal rareearth elements (REE) patterns observed for all harzburgitic, and some lherzolitic garnets, whereas eclogitic garnets form normal LREE-depleted patterns. These sinusoidal REE patterns are indicative of a complex petrogenesis for the garnets, involving partial-melting, followed by metasomatic enrichment, particularly of the LREEs/MREEs. The metasomatic agents were probably not those of carbonatitic fluids, but rather C-O-H-N-S fluids, as indicated by the negative anomalies of $\mathrm{Ba}$ and $\mathrm{Sr}$ in the garnets.

The general axiom among investigators that most, if not all, DIs are syngenetic with their diamonds is seriously questioned. The petrogenetic history of the harzburgitic garnet DIs involved complex processing prior to their diamond encapsulation. That is, the garnet DIs retained a signature of their earlier, pre-diamond encapsulation history. This result is taken as proof that basically all harzburgitic garnet DIs are non-syngenetic (i.e., protogenetic) with their host diamonds.
\end{abstract}

